\title{
Comparison of Ulnar Collateral Ligament Reconstruction Techniques in the Elbow of Sports Players
}

\author{
Jun-Gyu Moon, Hee-Dong Lee \\ Department of Orthopedic Surgery, Korea University Guro Hospital, Seoul, Korea
}

\begin{abstract}
Ulnar collateral ligament injuries have been increasingly common in overhead throwing athletes. Ulnar collateral ligament reconstruction is the current gold standard for managing ulnar collateral ligament insufficiency, and numerous reconstruction techniques have been described. Although good clinical outcomes have been reported regarding return to sports, there are still several technical issues including exposure, graft selection and fixation, and ulnar nerve management. This review article summarizes a variety of surgical techniques of ulnar collateral ligament reconstructions and compares clinical outcomes and biomechanics.
\end{abstract}

Keywords: Elbow; Ulnar collateral ligament; Reconstructive surgical procedures

\section{INTRODUCTION}

The ulnar collateral ligament (UCL) of the elbow is the primary restraint to valgus stress and is an important structure to overhead throwing athletes. Since the first description of UCL rupture in javelin throwers [1], interest in UCL injuries has increased due to both the epidemic of injury among patients involved in throwing sports and media interest in professional overhead throwing athletes.

Since Dr. Jobe first performed UCL reconstruction (UCLR) in 1974, and published his experience in 1986 [2], UCLR has been a popular treatment for insufficient UCL. There have been many modification and advancements in surgical techniques, and optimal UCLR continues to be a topic of debate. Despite use of various techniques of UCLR for UCL injuries, studies reviewing surgical techniques from the traditional to currently existing or new meth- ods are lacking. The purpose of this review was to address surgical techniques of UCLR by summarizing and comparing clinical outcomes and biomechanics.

\section{SURGICAL TECHNIQUES}

\section{Original Jobe Technique}

The first successful UCLR was performed by Frank Jobe (Kerlan-Jobe Orthopedic Clinic, Inglewood, CA, USA) on Los Angeles Dodgers pitcher Tommy John in 1974. After surgery, John resumed pitching at his pre-injury level. Jobe et al. [2] published their initial results in a population of baseball pitchers and javelin throwers in 1986. The original technique utilized the palmaris longus tendon or plantaris tendon as an autograft and required detachment of the flexor-pronator musculature at its origin and sub-

Received: August 5, $2019 \quad$ Accepted: February 7, 2020

Correspondence to: Jun-Gyu Moon

Department of Orthopedic Surgery, Korea University Guro Hospital, 148 Gurodong-ro, Guro-gu, Seoul 08308, Korea

Tel: +82-2-2626-3089, Fax: +82-2-2626-1164, E-mail: moonjg@korea.ac.kr, ORCID: https://orcid.org/0000-0002-8835-078X

Financial support: None.

Conflict of interest: None.

Copyright@ 2020 Korean Shoulder and Elbow Society. All Rights Reserved.

This is an Open Access article distributed under the terms of the Creative Commons Attribution Non-Commercial License (http://creativecommons.org/licenses/by-nc/4.0/) which permits unrestricted non-commercial use, distribution, and reproduction in any medium, provided the original work is properly cited. 
muscular transposition of the ulnar nerve. At the humeral origin of the UCL, two tunnels were created in a " $\mathrm{V}$ " configuration through the posterior cortex to configure the graft in a figure- 8 fashion. Two drill holes in the ulna and three in the medial epicondyle were made with a 3.2-mm drill bit (Fig. 1).

This series reported a $63 \%$ success rate (10 of 16 patients), as defined by return to preinjury or better level of participation in athletic activity. However, it was also associated with a $32 \%$ complication rate, primarily related to postoperative ulnar neuropathy. A later study by Conway et al. [3] of 56 UCLR cases with a mean 6.3 years of follow-up showed $68 \%$ excellent outcomes in which the patient was able to compete at the same or higher level as before the injury for $>12$ months.

\section{Modified Jobe Technique}

Due to the high rate of ulnar nerve complications, Jobe modified his technique using a muscle splitting approach without detaching the flexor-pronator, no ulnar nerve transposition, and larger humeral tunnel through the anterior cortex. He reported better outcomes, with $5 \%$ of patients experiencing transient ulnar nerve symptoms and 93\% showing an excellent result [4].

Andrews et al. [5] and Andrews and Timmerman [6] also used the Jobe technique, except with subcutaneous ulnar nerve transposition and combined arthroscopy. Exposure of the UCL was achieved with elevation of the flexor-pronator mass, and a humeral tunnel was made with a $3.5-\mathrm{mm}$ drill bit to create a Y-shaped tunnel configuration. Another study from the same institution showed excellent results in $81 \%$ of 78 baseball players who underwent UCRL [7]. In the largest series on UCLR to date, Cain et al. [8] reported on 1,281 patients treated with this technique. Among the

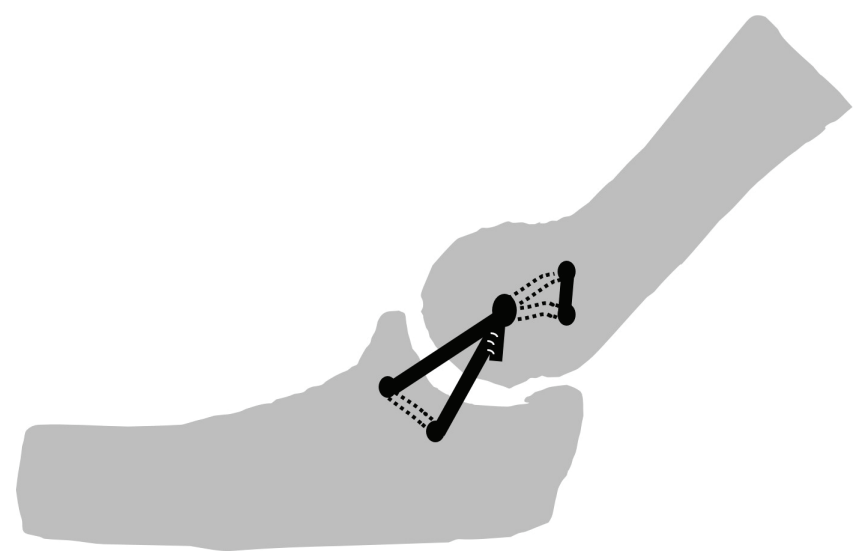

Fig. 1. Illustration of the original Jobe technique. A free tendon graft is pulled through the ulnar and humeral tunnel and forms a figure-8. It is then put under tension and sutured to itself.
733 individuals with reconstruction, $83 \%$ had excellent results and $16 \%$ developed transient ulnar nerve paresthesia, with most of these cases resolving within 6 weeks. Arthroscopic debridement of olecranon osteophytes was the most common additional surgery in $7.2 \%$ of patients. This modified technique was called the Andrews technique or the American Sports Medicine Institute (ASMI) modification.

\section{Docking Technique}

David Altchek developed the docking technique and reported results of the first 36 patients treated with this technique in 2002 [9]. Key elements of the docking technique included a muscle-splitting approach without routine transposition of the ulnar nerve, routine arthroscopic assessment, treatment of associated lesions, and docking the two ends of the tendon graft into a single humeral tunnel (Fig. 2). Rohrbough et al. [9] first described the docking technique and provided significant improvement of technical issues such as graft fixation and tensioning of the previous technique. They raised several concerns about the previous Jobe technique, which included the large drill holes within the limited area of the epicondyle, the difficulty in holding tension on the graft during fixation, and the strength of tendon fixation.

The ulnar tunnel is created in the same manner as in the Jobe technique. The humeral tunnel is created with a single inferior tunnel and two small superior exit tunnels, creating a Y-shaped tunnel. A 4.5-mm drill or burr is used to create a socket in the center of the footprint to a depth of $15 \mathrm{~mm}$. and two 1.5-mm sockets that converge to the single $4.5-\mathrm{mm}$ socket are drilled. The two $1.5-$ $\mathrm{mm}$ sockets should be just anterior to the medial intermuscular septum and at least 5 to $10 \mathrm{~mm}$ apart (Fig. 3) [10,11]. Dodson et al.

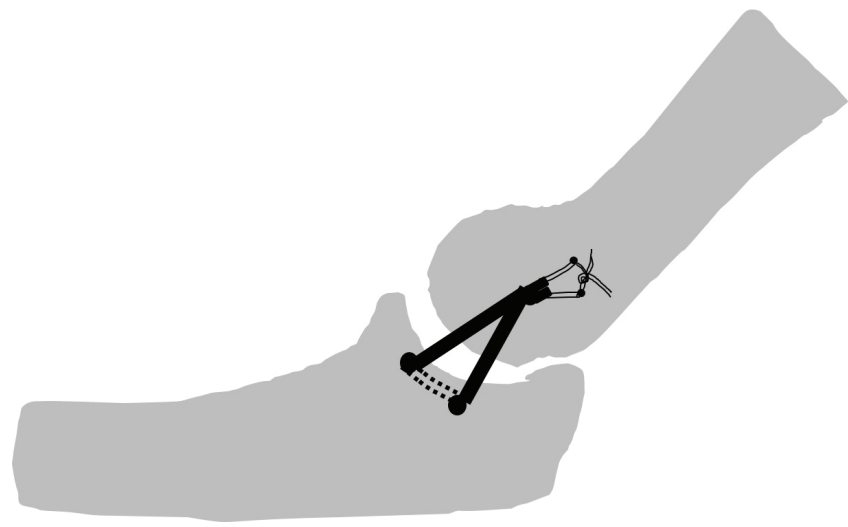

Fig. 2. Illustration of the docking technique. Two ulnar tunnels and a single humeral tunnel are created, followed by two small exit holes. Sutures of both limbs from the ulnar tunnel are tied over the humeral bony bridge. 
[11] reported that $90 \%$ of patients were able to return to their preinjury level of activity after UCLR with the docking technique.

\section{MODIFIED DOCKING TECHNIQUE}

Paletta and Wright [12] reported a case series using further modification of the docking technique using a four-strand palmaris longus graft, and 23 of 25 participants (92\%) were able to return to their preinjury levels of competition. Koh et al. [13] modified the docking technique using a three-strand construct with a double anterior bundle and a single posterior bundle. Bower et al. [14] described another three-strand docking technique with excess graft sutured to the anterior band, while tension was maintained on the excess graft. McGraw et al. [15] and Donohue et al. [16,17] reported a novel docking plus technique that used four strands of the palmaris longus tendon.

\section{David Altchek and Neal ElAttrache for Tommy John (DANE TJ) Technique}

In 2006, Conway [18] described a new procedure, the DANE TJ technique. This technique utilizes a combination of fixation techniques of docking fixation on the humeral side and interference screw fixation on the ulnar side (Table 1, Fig. 4). He preferred a gracilis tendon as autograft and used an interference screw (4.75-, 5.5-, 6.0-mm diameter) for ulnar side fixation. This technique originated from a biomechanical study using interference screws [18]. Ahmad et al. [19] demonstrated that the load to failure strength was $90 \%$ of that of the native ligament when the tendon graft was locked to the interference screw with sutures. The DANE TJ technique may be valuable when the sublime tubercle is compromised or a revision surgery is required. However, graft trauma from screw-graft-tunnel mismatch and proximal ulnar fracture is concerning. In addition, another biomechanical study showed that interference screw fixation did not provide sufficient fixation [20]. Dine et al. [21] reported excellent results in $86 \%$ of 22 athletes treated with this technique.

\section{Repair with or without an Internal Brace Augmentation}

Despite good clinical outcomes after UCLR, patients require a long recovery time prior to return to sports (RTS), which is a challenge for high-demand athletes. In addition, UCL injuries vary in degree, from partial tears to chronic complete tear. These observations imply that repair is an option for some athletes. Although initial data on UCL repair demonstrated poor outcomes, recent studies showed promising results in symptomatic UCL injury to the proximal or distal end of the ligament. Savoie et al. [22] reported $93 \%$
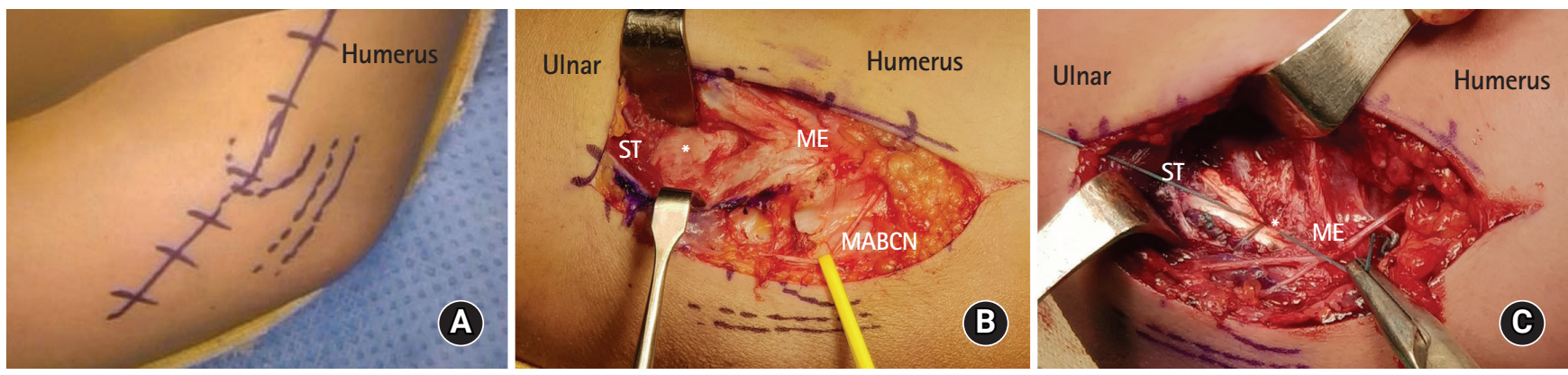

Fig. 3. (A) The skin incision is $8 \mathrm{~cm}$ centered over the medical epicondyle. (B) Longitudinal splitting of the flexor pronator muscle exposes an ulnar collateral ligament (asterisk). (C) When the docking suture is tied, the tension on the graft may be supported with a yolk stitch (asterisk). ST, sublime tubercle; $\mathrm{ME}$, medial epicondyle; $\mathrm{MABCN}$, medial antebrachial cutaneous nerve.

Table 1. Three UCL reconstruction techniques and their differences

\begin{tabular}{|c|c|c|c|c|c|c|c|}
\hline Technique & Inventor & $\begin{array}{c}\text { Year } \\
\text { published }\end{array}$ & $\begin{array}{c}\text { FPM } \\
\text { approach }\end{array}$ & $\begin{array}{c}\text { Graft } \\
\text { configuration }\end{array}$ & $\begin{array}{l}\text { Ulnar preparation } \\
\text { fixation }\end{array}$ & $\begin{array}{l}\text { Humeral preparation } \\
\text { fixation }\end{array}$ & $\begin{array}{l}\text { Ulnar nerve } \\
\text { treatment }\end{array}$ \\
\hline \multirow[t]{2}{*}{ Jobe [2] } & Frank Jobe & 1986 & Transection & Figure-8 & Tunnel & Tunnel & $\begin{array}{l}\text { Submuscular transpo- } \\
\text { sition }\end{array}$ \\
\hline & & & & & None & Suture to tendon & \\
\hline \multirow[t]{2}{*}{ Docking [9] } & David Altchek & 2002 & Split & Triangle & Tunnel & Socket & Only if symptomatic \\
\hline & & & & & None & Suture over bridge & \\
\hline \multirow[t]{2}{*}{ DANE TJ [18] } & David Altchek, & 2006 & Split & Linear & Socket & Socket & Only if symptomatic \\
\hline & Neal ElAttrache & & & & Interference screw & Docking over bridge & \\
\hline
\end{tabular}

UCL, ulnar collateral ligament; FPM, flexor pronator muscle; DANE TJ, David Altchek and Neal ElAttrache for Tommy John. 


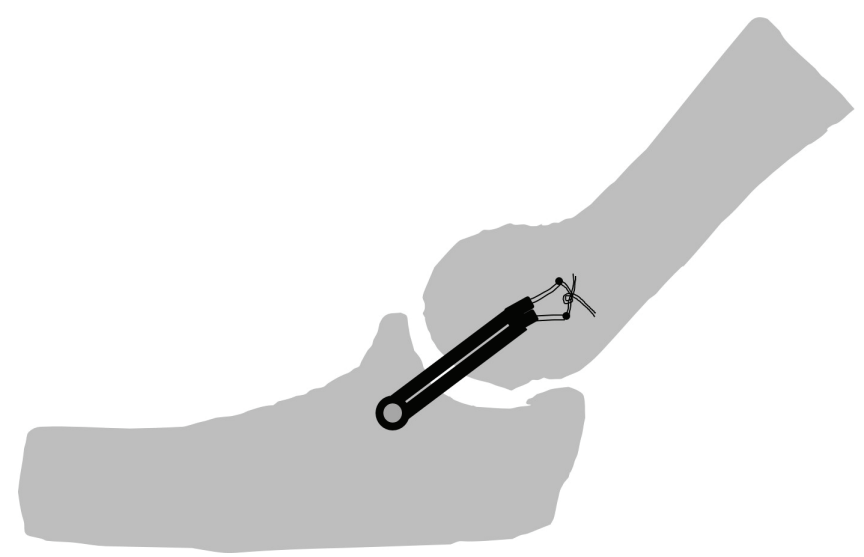

Fig. 4. Illustration of the David Altchek and Neal ElAttrache for Tommy John (DANE TJ) technique. This technique utilizes a combination of fixation techniques. On the ulnar side, an interference screw is fixed with a single drill hole; on the humeral side, docking fixation is used.

good to excellent results, and $97 \%$ of patients RTS after repair using suture anchors with arthroscopic assistance.

\section{Alternative Technique}

Hechtman et al. [23] described a hybrid technique that uses an ulnar osseous tunnel and suture anchor fixation on the humerus and reported that their method closely reproduced the normal anatomy without any marked difference in reconstruction strength compared with traditional bone tunnels. Savoie et al. [24] and Hurt et al. [25] reported the short-term outcomes of 116 patients who underwent UCLR with hamstring allograft. Myeroff et al. [26] and Acevedo et al. [27] described UCLR using cortical buttons on humeral and ulnar fixation that create a single tunnel. This technique may offer an alternative solution to bony insufficiency in revision surgery.

\section{BIOMECHANICAL STUDIES}

There have been biomechanical studies comparing the native UCL with reconstructive UCL and UCLR techniques for clinical applications. As in native elbow, the valgus stability of UCLR elbow can vary with flexion angle [28]. Mullen et al. [29] found that UCLR with Jobe technique had stability similar to the native UCL at flexion angles of $30^{\circ}-90^{\circ}$. However, Ciccotti et al. [30] showed that UCLR with modified Jobe and docking technique provided valgus stability at flexion angles $>90^{\circ}$. Paletta et al. [31] compared stability of UCLR with that of the Jobe technique with a four-strand docking technique and concluded that the docking technique can provide greater initial stability. Ahmad et al. [19] evaluated the sta- bility of interference screw fixation and found the average ultimate moment of UCLR with interference screw was $95 \%$ of that of native UCL. However, Armstrong et al. [20] performed a biomechanical comparison of native ligament strength, the docking and Jobe techniques, interference screw fixation, and reconstruction with an Endobutton and concluded that UCLR with either the docking technique or Endobutton may be the best option biomechanically. The authors also expressed concerns over graft rupture with interference screw fixation. McAdams et al. [32] compared cyclical valgus stability of the docking technique and interference screw fixation. Valgus stability was greater with interference screw fixation at early cycles, but no difference was found at 1,000 cycles. The tension slide technique involves a single ulnar bone tunnel with a tendon graft attached to a cortical button and use of interference screw. In a cadaveric study, biomechanical results showed superiority of strength and stiffness of ulnar fixation with the bone tunnel technique [33].

Recently, several biomechanical studies have evaluated valgus stability of an internal brace combined with UCRL or repair [3438]. Most studies demonstrated augmentation with an internal brace providing stability similar to that of the docking technique or more resistance to the valgus load. These results support use of repair or reconstruction with an internal brace technique for UCL insufficient patients. One systemic review about biomechanical testing with UCLR showed that the most common mode of failure following UCLR in a laboratory setting was suture failure. While failure of the graft represented $27 \%$ and bone tunnel fracture was $14 \%$ of the failure, suture failure was much higher at 51\% [24].

\section{SPORTS PERFORMANCE OUTCOMES}

Jobe and various modifications and biomechanical studies have demonstrated that UCLR can appropriately restore elbow stability and provide superior outcomes in UCL insufficient athletes. However, while athletes who underwent UCLR can RTS, players who return to pre-injury level are not numerous. Erickson et al. [39] evaluated the performance of 179 major league baseball (MLB) pitchers on RTS and found that they pitched fewer innings in a season and had fewer wins and losses per season compared to before surgery. Furthermore, Jiang and Leland [40] and Lansdown and Feeley [41] reported small, but statistically significant, decreases in velocity of fastball and changeup pitches thrown by pitchers who return to MLB after UCLR from pre-injury to post-injury years [42]. In addition, there is increase in number of UCLR revisions among primary UCLR athletes, and performance and longevity after revision surgery decrease [46] (Table 2). 
Table 2. Summary of clinical outcomes of UCLR

\begin{tabular}{|c|c|c|c|c|c|}
\hline Study & UCLR technique & $\begin{array}{l}\text { No. of } \\
\text { cases }\end{array}$ & $\begin{array}{c}\text { Mean } \\
\text { follow-up }\end{array}$ & Rate of RTS (\%) & Complication \\
\hline Jobe et al. (1986) [2] & Jobe & 16 & $51 \mathrm{mo}$ & 63 & 3 (Reop) \\
\hline Azar et al. (2000) [7] & ASMI & 78 & $35 \mathrm{mo}$ & 79 & 8 (4 Donor site, 2 reop, 1 infection, $1 \mathrm{UN}$ ) \\
\hline Thompson et al. (2001) [4] & Modified Jobe & 33 & $2 \mathrm{yr}$ & 100 & $5 \% \mathrm{UN}$ \\
\hline Rohrbough et al. (2002) [9] & Docking & 36 & $3.3 \mathrm{yr}$ & 92 & 2 (1 Hematoma, $1 \mathrm{UN})$ \\
\hline Dodson et al. (2006) [11] & Docking & 100 & $36 \mathrm{mo}$ & 96 & 3 (2 UN, 1 stiffness) \\
\hline Dine et al. (2007) [21] & DANE TJ & 22 & $35.9 \mathrm{mo}$ & 86 & 4 (2 UN, 2 stiffness) \\
\hline Cain et al. (2010) [8] & ASMI & 743 & $38.4 \mathrm{mo}$ & 83 & 148 (121 UN, 55 reop for osteophyte) \\
\hline Hechtman et al. (2011) [23] & Hybrid & 34 & $6.9 \mathrm{yr}$ & 85 & $1(\mathrm{UN})$ \\
\hline Dugas et al. (2012) [43] & ASMI & 120 & $>2 \mathrm{yr}$ & 87.5 & 42 (25 UN, 8 reop) \\
\hline Savoie et al. (2013) [24] & Jobe, docking & 116 & $39 \mathrm{mo}$ & 95 & $\begin{array}{l}7 \text { ( } 3 \mathrm{UN}, 2 \text { wound, } 1 \text { med epicondylar } \\
\text { fracture, } 1 \text { tendon tear) }\end{array}$ \\
\hline Erickson et al. (2016) [44] & Docking, double docking & 188 & $60 \mathrm{mo}$ & 94.1 & 10 (reop) \\
\hline Myeroff et al. (2018) [26] & Cortical button & 23 & $42.7 \mathrm{mo}$ & 82.6 & 1 Failure \\
\hline Donohue et al. (2019) [16] & Docking plus & 324 & $>24 \mathrm{mo}$ & 90.9 & $28 \mathrm{UN}, 8$ retear, 18 reop \\
\hline Dugas at al. (2019) [45] & Repair with internal brace & 111 & $>12 \mathrm{mo}$ & 92 & 5 (3 UN, 1 heterotopic bone, 1 retear) \\
\hline
\end{tabular}

UCLR, ulnar collateral ligament reconstruction; RTS, return to sports; Reop, reoperation; ASMI, American Sports Medicine Institute; UN, ulnar neuropathy; DANE TJ, David Altchek and Neal ElAttrache for Tommy John.

\section{CONCLUSION}

Since the first UCLR surgery in 1974, several modifications and new techniques for UCL injuries for athletes have been proposed. The Jobe technique and modified Jobe technique, docking technique and modified docking technique, and DANE TJ technique have been most often used for UCLR surgery. Clinical studies have reported successful outcomes and a high rate of RTS in overhead throwing athletes. Several modifications including flexor pronator muscle splitting approach and minimal handling of the ulnar nerve might improve outcomes. Newer fixation techniques such as augmentation with an internal brace may allow a faster RTS. Finally, with the perception of lower performance after surgery, efforts are needed to focus on education and injury prevention.

\section{ORCID}

$\begin{array}{ll}\text { Jun-Gyu Moon } & \text { https://orcid.org/0000-0002-8835-078X } \\ \text { Hee-Dong Lee } & \text { https://orcid.org/0000-0002-9457-4317 }\end{array}$

\section{REFERENCES}

1. Waris W. Elbow injuries of javelin-throwers. Acta Chir Scand 1946;93:563-75.

2. Jobe FW, Stark H, Lombardo SJ. Reconstruction of the ulnar collateral ligament in athletes. J Bone Joint Surg Am 1986;68:115863.
3. Conway JE, Jobe FW, Glousman RE, Pink M. Medial instability of the elbow in throwing athletes: treatment by repair or reconstruction of the ulnar collateral ligament. J Bone Joint Surg Am 1992;74:67-83.

4. Thompson WH, Jobe FW, Yocum LA, Pink MM. Ulnar collateral ligament reconstruction in athletes: muscle-splitting approach without transposition of the ulnar nerve. J Shoulder Elbow Surg 2001;10:152-7.

5. Andrews JR, Jost PW, Cain EL. The ulnar collateral ligament procedure revisited: the procedure we use. Sports Health 2012;4:438-41.

6. Andrews JR, Timmerman LA. Outcome of elbow surgery in professional baseball players. Am J Sports Med 1995;23:407-13.

7. Azar FM, Andrews JR, Wilk KE, Groh D. Operative treatment of ulnar collateral ligament injuries of the elbow in athletes. Am J Sports Med 2000;28:16-23.

8. Cain EL Jr, Andrews JR, Dugas JR, Wilk KE, McMichael CS, Walter JC 2nd, et al. Outcome of ulnar collateral ligament reconstruction of the elbow in 1281 athletes: results in 743 athletes with minimum 2-year follow-up. Am J Sports Med 2010;38: 2426-34.

9. Rohrbough JT, Altchek DW, Hyman J, Williams RJ 3rd, Botts JD. Medial collateral ligament reconstruction of the elbow using the docking technique. Am J Sports Med 2002;30:541-8.

10. Camp CL, Dines JS, Voleti PB, James EW, Altchek DW. Ulnar collateral ligament reconstruction of the elbow: the docking technique. Arthrosc Tech 2016;5:e519-23. 
11. Dodson CC, Thomas A, Dines JS, Nho SJ, Williams RJ 3rd, Altchek DW. Medial ulnar collateral ligament reconstruction of the elbow in throwing athletes. Am J Sports Med 2006;34:1926-32.

12. Paletta GA Jr, Wright RW. The modified docking procedure for elbow ulnar collateral ligament reconstruction: 2-year follow-up in elite throwers. Am J Sports Med 2006;34:1594-8.

13. Koh JL, Schafer MF, Keuter G, Hsu JE. Ulnar collateral ligament reconstruction in elite throwing athletes. Arthroscopy 2006;22: 1187-91.

14. Bowers AL, Dines JS, Dines DM, Altchek DW. Elbow medial ulnar collateral ligament reconstruction: clinical relevance and the docking technique. J Shoulder Elbow Surg 2010;19:110-7.

15. McGraw MA, Kremchek TE, Hooks TR, Papangelou C. Biomechanical evaluation of the docking plus ulnar collateral ligament reconstruction technique compared with the docking technique. Am J Sports Med 2013;41:313-20.

16. Donohue BF, Lubitz MG, Kremchek TE. Elbow ulnar collateral ligament reconstruction using the novel docking plus technique in 324 athletes. Sports Med Open 2019;5:3.

17. Donohue BF, Lubitz MG, Kremchek TE. Elbow ulnar collateral ligament reconstruction using a 4-strand docking plus technique. Arthrosc Tech 2017;6:e1201-9.

18. Conway JE. The DANE TJ procedure for elbow medial ulnar collateral ligament insufficiency. Tech Shoulder Elb Surg 2006;7:36-43.

19. Ahmad CS, Lee TQ, ElAttrache NS. Biomechanical evaluation of a new ulnar collateral ligament reconstruction technique with interference screw fixation. Am J Sports Med 2003;31:332-7.

20. Armstrong AD, Dunning CE, Ferreira LM, Faber KJ, Johnson JA, King GJ. A biomechanical comparison of four reconstruction techniques for the medial collateral ligament-deficient elbow. J Shoulder Elbow Surg 2005;14:207-15.

21. Dines JS, ElAttrache NS, Conway JE, Smith W, Ahmad CS. Clinical outcomes of the DANE TJ technique to treat ulnar collateral ligament insufficiency of the elbow. Am J Sports Med 2007; 35:2039-44.

22. Savoie FH 3rd, Trenhaile SW, Roberts J, Field LD, Ramsey JR. Primary repair of ulnar collateral ligament injuries of the elbow in young athletes: a case series of injuries to the proximal and distal ends of the ligament. Am J Sports Med 2008;36:1066-72.

23. Hechtman KS, Zvijac JE, Wells ME, Botto-van Bemden A. Longterm results of ulnar collateral ligament reconstruction in throwing athletes based on a hybrid technique. Am J Sports Med 2011;39:342-7.

24. Savoie FH 3rd, Morgan C, Yaste J, Hurt J, Field L. Medial ulnar collateral ligament reconstruction using hamstring allograft in overhead throwing athletes. J Bone Joint Surg Am 2013;95:1062-
6.

25. Hurt JA 3rd, Savoie FH 3rd, O'Brien MJ. Surgical technique: medial ulnar collateral ligament reconstruction using hamstring allograft. JBJS Essent Surg Tech 2013;3:e23.

26. Myeroff C, Brock JL, Huffman GR. Ulnar collateral ligament reconstruction in athletes using a cortical button suspension technique. J Shoulder Elbow Surg 2018;27:1366-72.

27. Acevedo DC, Lee B, Mirzayan R. Novel technique for ulnar collateral ligament reconstruction of the elbow. Orthopedics 2012;35:947-51.

28. Callaway GH, Field LD, Deng XH, et al. Biomechanical evaluation of the medial collateral ligament of the elbow. J Bone Joint Surg Am 1997;79:1223-31.

29. Mullen DJ, Goradia VK, Parks BG, Matthews LS. A biomechanical study of stability of the elbow to valgus stress before and after reconstruction of the medial collateral ligament. J Shoulder Elbow Surg 2002;11:259-64.

30. Ciccotti MG, Siegler S, Kuri JA 2nd, Thinnes JH, Murphy DJ 4th. Comparison of the biomechanical profile of the intact ulnar collateral ligament with the modified Jobe and the Docking reconstructed elbow: an in vitro study. Am J Sports Med 2009;37:97481.

31. Paletta GA Jr, Klepps SJ, Difelice GS, et al. Biomechanical evaluation of 2 techniques for ulnar collateral ligament reconstruction of the elbow. Am J Sports Med 2006;34:1599-603.

32. McAdams TR, Lee AT, Centeno J, Giori NJ, Lindsey DP. Two ulnar collateral ligament reconstruction methods: the docking technique versus bioabsorbable interference screw fixation:a biomechanical evaluation with cyclic loading. J Shoulder Elbow Surg 2007;16:224-8.

33. Jackson A, Maerz T, Koueiter DM, Andrecovich CJ, Baker KC, Anderson K. Strength of ulnar fixation in ulnar collateral ligament reconstruction: a biomechanical comparison of traditional bone tunnels to the tension-slide technique. J Shoulder Elbow Surg 2012;21:1674-9.

34. Bernholt DL, Lake SP, Castile RM, Papangelou C, Hauck O, Smith MV. Biomechanical comparison of docking ulnar collateral ligament reconstruction with and without an internal brace. J Shoulder Elbow Surg 2019;28:2247-52.

35. Bodendorfer BM, Looney AM, Lipkin SL, et al. Biomechanical comparison of ulnar collateral ligament reconstruction with the docking technique versus repair with internal bracing. Am J Sports Med 2018;46:3495-501.

36. Leasure J, Reynolds K, Thorne M, Escamilla R, Akizuki K. Biomechanical comparison of ulnar collateral ligament reconstruction with a modified docking technique with and without suture augmentation. Am J Sports Med 2019;47:928-32. 
37. Dugas JR, Walters BL, Beason DP, Fleisig GS, Chronister JE. Biomechanical comparison of ulnar collateral ligament repair with internal bracing versus modified Jobe reconstruction. Am J Sports Med 2016;44:735-41.

38. Jones CM, Beason DP, Dugas JR. Ulnar collateral ligament reconstruction versus repair with internal bracing: comparison of cyclic fatigue mechanics. Orthop J Sports Med 2018;6: 2325967118755991.

39. Erickson BJ, Gupta AK, Harris JD, et al. Rate of return to pitching and performance after Tommy John surgery in Major League Baseball pitchers. Am J Sports Med 2014;42:536-43.

40. Jiang JJ, Leland JM. Analysis of pitching velocity in major league baseball players before and after ulnar collateral ligament reconstruction. Am J Sports Med 2014;42:880-5.

41. Lansdown DA, Feeley BT. The effect of ulnar collateral ligament reconstruction on pitch velocity in Major League Baseball pitch- ers. Orthop J Sports Med 2014;2:2325967114522592.

42. Ahmad CS, Grantham WJ, Greiwe RM. Public perceptions of Tommy John surgery. Phys Sportsmed 2012;40:64-72.

43. Dugas JR, Bilotta J, Watts CD, et al. Ulnar collateral ligament reconstruction with gracilis tendon in athletes with intraligamentous bony excision: technique and results. Am J Sports Med 2012;40:1578-82.

44. Erickson BJ, Bach BR Jr, Cohen MS, et al. Ulnar collateral ligament reconstruction: the rush experience. Orthop J Sports Med 2016;4:2325967115626876.

45. Dugas JR, Looze CA, Capogna B, et al. Ulnar collateral ligament repair with collagen-dipped fibertape augmentation in overhead-throwing athletes. Am J Sports Med 2019;47:1096-102.

46. Wilson AT, Pidgeon TS, Morrell NT, DaSilva MF. Trends in revision elbow ulnar collateral ligament reconstruction in professional baseball pitchers. J Hand Surg Am 2015;40:2249-54. 